\title{
ir
}

\section{SOBRE EL TEXTO DE EL MAYOR ENCANTO, AMOR: A PROPÓSITO DE UN MANUSCRITO DE 1668}

\author{
Fernando Rodríguez-Gallego \\ Universidad de Santiago de Compostela ${ }^{1}$ \\ [Anuario calderoniano (ISSN: 1888-8046), 1, 2008, pp. 285-315]
}

El mayor encanto, amor fue la primera comedia de Calderón escrita para la corte. Se le encargó para ser representada, por la compañía de Roque de Figueroa y con escenografia de Cosme Lotti, en el estanque del Buen Retiro en la noche de San Juan de $1635^{2}$ y constituyó un enorme éxito, por lo que a Calderón se le volvió a encargar la fiesta de San Juan al año siguiente, ocasión para la que escribió Los tres mayores prodigios. Con El mayor encanto abrió Calderón su Segunda

${ }^{1}$ El autor del artículo es beneficiario de una beca del Programa Nacional de Formación de Profesorado Universitario (FPU) del Ministerio de Educación y Ciencia. El trabajo se inscribe en el Proyecto de investigación sobre la obra de Calderón de la Barca financiado por la DGICYT BFF2001-3168, continuación del concedido por la Secretaría Xeral de Investigación e Desenvolvemento de la Xunta de Galicia PGIDT01PXI20406PR, y renovado por el HUM2004-03952, que recibe fondos FEDER y cuyo investigador principal es Luis Iglesias Feijoo. Quisiera también dejar constancia de mi agradecimiento a John O'Neill, Edwin, William, Rober y demás personal de la biblioteca de la Hispanic Society of America.

${ }^{2}$ Así se indica en la tabla de contenidos de la Segunda parte de Calderón, en la que se publicó la comedia. El estreno, sin embargo, se retrasó, aunque sobre la fecha exacta en que finalmente se produjo no existe acuerdo entre los estudiosos. Shergold, 1958, así como un estado de la cuestión en Fernández Mosquera, en prensa b. 
parte de comedias, publicada en 1637, prueba de la estima en la que debía de tener esta obra.

Sin embargo, tal aprecio temprano hacia el El mayor encanto no se ha visto reflejado posteriormente y hoy en día no se la incluye entre las comedias que forman el canon calderoniano. De hecho, no cuenta con ediciones modernas, y para leerla hay que recurrir a las colecciones editadas en el siglo XIX por Hartzenbusch y en el xx porValbuena Briones ${ }^{3}$. Sólo en años recientes se le ha otorgado un mayor grado de atención a partir de cuestiones interpretativas, pues algunos estudiosos han visto en El mayor encanto un texto en el que Calderón, bajo la trama mitológica, formulaba diferentes críticas a Felipe IV y Olivares, aunque esta postura ha sido rebatida por otros autores ${ }^{4}$.

En cuanto al texto, El mayor encanto ha gozado de una atención que podríamos denominar parcial. En las primeras décadas del siglo Xx fue utilizada por estudiosos como Toro y Gisbert o Heaton ${ }^{5}$ para establecer la situación de las ediciones de la Segunda parte publicadas en el siglo XVII, pues unos versos del inicio de la comedia sólo están presentes en una de las que tienen fecha de 1637, la príncipe conocida desde Heaton como QC, pero están ausentes de la otra, la contrahecha unos treinta años posterior conocida como $Q$, así como de la de Vera Tassis de 1686 y de todas las que la siguieron hasta la de Valbuena Briones, que los recuperó ${ }^{6}$. A partir de estas diferencias entre el texto de $Q C$ y el de $Q$ Heaton llegó a aventurar una posible intervención de don Pedro, o incluso de Vera Tassis, en la elaboración de $Q^{7}$, algo que fue rebatido por Sloman en un artículo ${ }^{8}$ que puso fin a este debate.

3 Pronto, sin embargo, aparecerá publicada en la edición de la Segunda parte de Calderón preparada por Fernández Mosquera. Por su parte, Alejandra Ulla Lorenzo dedica su tesis doctoral a la edición crítica de las dos fiestas de Calderón incluidas en la Segunda parte: El mayor encanto, amor y Los tres mayores prodigios.

${ }^{4}$ Como representantes de la primera tendencia mencionada puede citarse a De Armas, 1986, o Greer, 1991, y de la segunda a Fernández Mosquera, en prensa a y b.

5 Toro y Gisbert, 1918, y Heaton, 1937.

${ }^{6}$ Valbuena Briones, 1966. Curiosamente, ya Hartzenbusch, 1944, p. 594c, n. 1, en su edición de la comedia, que seguía la de Vera Tassis, detectó con agudeza que debían de faltar algunos versos a los que se aludía en un pasaje posterior del texto. Esos versos, en efecto, sí estaban presentes en la edición príncipe de El mayor encanto.

${ }^{7}$ Heaton, 1937, p. 224.

8 Sloman, 1963. 
Los problemas textuales de El mayor encanto no se volvieron a tener presentes hasta un artículo de Germán Vega García-Luengos de nuevo sobre la Segunda parte ${ }^{9}$. En su artículo Vega, tratando de las dificultades que habrían podido tener los hermanos Calderón durante el proceso de reunión de las comedias que compusieron la Segunda parte y de la posible mala calidad de éstas al llegar a sus manos, sugería que de este problema tal vez se librasen El mayor encanto, amor y Los tres mayores prodigios, cuyos originales quizá conservase Calderón por haber sido representadas en fechas próximas a las de publicación en sendas fiestas de palacio ${ }^{10}$.

El cotejo de los testimonios muestra, sin embargo, una realidad diferente. El mayor encanto como Los tres mayores prodigios cuentan con más de cien errores en la Segunda parte, por lo que su edición exige más enmiendas de las habituales en otras comedias de la parte, que suelen presentar entre cincuenta y ochenta errores. Cabría preguntarse, entonces, por qué, frente a lo previsible, el texto de estas dos fiestas es peor que el de otras comedias del mismo volumen, y la respuesta puede ser la misma que se daba para explicar la hipótesis contraria. Quizá sea muy aventurado pensarlo, pero Calderón, al hacerse con una comedia para publicarla, bien podría haber aprovechado esa oportunidad para revisarla más a fondo y reescribirla en mayor o menor medida en caso de que estuviese en mal estado, como pudo haber sucedido con Judas Macabeo o El astrólogo fingido, que cuentan, sobre todo esta última, con bastantes menos errores de los habituales en la parte ${ }^{11}$. Las fiestas, al contrario, por estar tan cercana la fecha de su estreno, quizá llegasen a la imprenta directamente de las compañías que las montaron e incluyesen ya distintos errores debidos a las copias utilizadas durante las representaciones que finalmente no fueron subsanados en el proceso de impresión.

De todas maneras, la tradición textual de las dos fiestas no se reduce a la Segunda parte, sino que ambas cuentan con manuscritos: el de El mayor encanto, repartido entre la Biblioteca Nacional de España

${ }^{9}$ Vega, 2002.

${ }^{10}$ Vega, 2002, pp. 39-40. De la misma opinión era Fernández Mosquera, 2005, pp. 315-316.

11 Sobre las dos versiones de El astrólogo fingido puede verse Rodríguez-Gallego, 2006. 
y la de la Hispanic Society of America, tiene censuras de noviembre de 1668, y el de Los tres mayores prodigios, conservado en la BNE, de junio y julio de 1669. Las censuras las firman Fermín de Sarassa y Francisco de Avellaneda en ambos casos, al igual que sucede con otros manuscritos de comedias calderonianas de esos mismos años.

Los manuscritos de las dos fiestas, además de los censores, comparten también al copista, identificado por Paz y Mélia con Matos Fragoso $^{12}$, atribución que ha sido puesta en duda con buenos argumentos por Sánchez Mariana centrándose en el caso de El mayor encanto $^{13}$, aunque sus conclusiones son válidas para el de Los tres mayores prodigios. De la misma mano son también las jornadas II y III del de El José de las mujeres conservado en la Hispanic, así como otros treinta manuscritos, enteros o sólo en parte, de la Nacional ${ }^{14}$, entre ellos el de El alcaide de sí mismo.

Sánchez Mariana llamó la atención sobre el manuscrito de El mayor encanto conservado en la BNE debido a que en su último folio cuenta con un autógrafo de Calderón. En efecto, los versos finales de la comedia aparecen tachados en el manuscrito, y al margen, de puño y letra de Calderón, figuran unos alternativos que simplifican en gran medida su representación, muy espectacular en la versión primera, motivo por el cual quizá se le solicitase al dramaturgo un final nuevo ${ }^{15}$.

12 Paz y Mélia no conoció el manuscrito de El mayor encanto, por lo que la atribución se basa en otros debidos a la misma mano, por ejemplo el de Los tres mayores prodigios (núm. 3613 del Catálogo).

13 Sánchez Mariana, 1984, pp. 127-130.

14 Ofrece la relación de los de la Nacional Sánchez Mariana, 1984, pp. 124-26.

15 El mismo Sánchez Mariana, en un trabajo posterior, 1993, p. 448, y tratando de este Seudo Matos Fragoso, explica que «en el manuscrito de El vaquero de Granada, de Diamante (de 1662 [BNE, ms. 17308]), copió el Seudo Matos la primera jornada, y [Sebastián de] Alarcón la segunda y tercera, según se dice, «de su original, por mandado de Antonio de Escamilla». Parece indudable que el Seudo Matos trabajaba para una compañía (en algunas de las copias figura la censura para la representación) y quizá en contacto directo con los dramaturgos. Como ejemplo de esto último menciona Sánchez Mariana la jornada tercera de El mayor encanto, amor. Por otra parte, en su trabajo de 1984, pp. 124-125, al listar los manuscritos copiados por el Seudo Matos, escribía Sánchez Mariana que el de El monstruo de los jardines (BNE Res. 96), de mano del Seudo Matos en la jornada primera y parte de la segunda, «lleva también correcciones autógrafas de Calderón", por lo que se trataría de un caso análogo al de la tercera jornada de El mayor encanto, amor. 
En otros lugares de esta tercera jornada hay diversas anotaciones y correcciones que parecen hechas de la misma tinta y de la misma mano, aunque el análisis de Sánchez Mariana descartó que fuesen de Calderón, conclusión a la que he llegado también con respecto a las anotaciones que hay en las jornadas primera y segunda conservadas en la Hispanic. Calderón parece, pues, haber limitado su intervención a estos versos finales y quizá no mirase el resto de la comedia, algo que explicaría la considerable cantidad de errores presentes en el manuscrito y que pasaron inadvertidos a revisores posteriores.

Pero junto a este autógrafo calderoniano, el manuscrito de El mayor encanto cuenta con otras curiosidades. La primera y más llamativa el estar repartido: las dos primeras jornadas en la Hispanic Society of America bajo la signatura B2614, en tanto que la tercera jornada, la estudiada por Sánchez Mariana, que desconocía entonces la existencia de las otras dos en la Hispanic, está en la Biblioteca Nacional de España con la signatura ms. 21264/1. Sánchez Mariana se percató años después de tal circunstancia ${ }^{16}$, algo que tampoco debe extrañar teniendo en cuenta que el manuscrito de la Nacional aún no figura en el catálogo electrónico de la biblioteca y que la comedia no ha sido objeto hasta el momento de ninguna edición crítica; así, la edición de El mayor encanto que acaba de finalizar Santiago Fernández Mosquera ${ }^{17}$, aunque basada en la Segunda parte, será la primera en tener en cuenta el manuscrito.

Este manuscrito partido parece corresponderse con uno del que daba noticia Cayetano Alberto de la Barrera, quien apuntaba que don José Sancho Rayón, ilustre bibliófilo del siglo XIX, poseía «un manuscrito antiguo, con una escena que se halla suprimida en todas las ediciones» ${ }^{18}$. Tal escena podría ser la del inicio que fue suprimida en la edición contrahecha $Q$, en la de Vera Tassis y sucesivas hasta la de Hartzenbusch inclusive, aunque sí está en la princeps, QC, y en $S$, la reedición de la Segunda parte de $1641^{19}$. Tal escena, de hecho, aparece atajada a lápiz y con una indicación de «ojo» en la parte del manus-

16 Sánchez Mariana, 1989, p. 73.

17 Fernández Mosquera, en prensa c.

18 C. Alberto de la Barrera, 1860, p. 513.

${ }^{19} \mathrm{Al}$ igual que $\mathrm{QC}$ y $\mathrm{Q}$, tomo la sigla $S$ para referirme a la edición de 1641 también de Heaton, 1937. 
crito conservada en la Hispanic, en lo que parece ser una anotación bastante moderna de alguien, quizá incluso del mismo Sancho Rayón o de La Barrera, que se percató de esta variación con respecto a las ediciones de la comedia que circulaban.

Que el manuscrito de Sancho Rayón y, al menos, el de la Hispanic son el mismo parece probarlo también la trayectoria seguida por los libros del bibliófilo. Tras su muerte su biblioteca pasó a engrosar la del marqués de Jerez de los Caballeros ${ }^{20}$, que a su vez fue comprada por Archer M. Huntington, en lo que constituye la base principal de la biblioteca de la Hispanic Society of America. Lo que no resulta tan fácil de delimitar es la procedencia de la parte conservada en Madrid ${ }^{21}$,

${ }^{20}$ Sin embargo, en el Catálogo de la biblioteca del marqués de Jerez de los Caballeros no figura el manuscrito, aunque da la impresión de que en él sólo se recogen impresos. En todo caso, según señala Rodríguez-Moñino en el prólogo de la edición facsímil, la segunda edición corregida del catálogo apareció en 1901, y entonces aún no había comprado el marqués la biblioteca de Sancho Rayón. Escribe RodríguezMoñino, 1966, p. 60, tratando sobre una carta enviada por el marqués a Serrano Morales: «Ya estaba concluida la lista [alude al Catálogo] en 28 de diciembre de 1901, fecha en la cual envía [el marqués] un ejemplar a su amigo Serrano Morales. La otra noticia importante está expresada así: «tengo en tratos una de las mejores bibliotecas que quedan en España, en la que hay preciosidades, tanto de impresos como de manuscritos. Pronto (D. m.) estará en mi poder». ¿Qué colección extraordinaria era esta? Para nosotros no cabe duda de que se trataba de la de don José Sancho Rayón». Sancho Rayón muere el 27 de enero de 1900, y dice Rodríguez-Moñino, 1966, p. 62: «Creemos firmemente que ambos bibliófilos [el marqués y Sancho Rayón] tenían ya echadas las bases de una venta por cuanto muy poco después las existencias que poseían los herederos de Sancho pasaron a manos del infatigable colector sevillano". En la misma página apunta Rodríguez-Moñino que otro bibliófilo «sacó tajada del pegujal de Sancho: don Marcelino Menéndez y Pelayo, a quien el Marqués cedió una gran parte de los autógrafos gallardescos y algunos libros que ya poseía en su biblioteca».

${ }^{21}$ En la Biblioteca Nacional me comunicaron que no tienen constancia ni de la procedencia ni de la fecha de adquisición del manuscrito. Debe notarse que en la primera edición del Catálogo de las piezas de teatro de la Nacional preparado por Paz y Mélia y aparecido en 1899 no figura el manuscrito de El mayor encanto, lo que posiblemente sea indicio de que por entonces aún no estaba en la biblioteca. Quizá valga también la pena mencionar, aunque se trate de una noticia indirecta, que la gran mayoría de manuscritos copiados por el seudo Matos Fragoso, amanuense también de El mayor encanto, conservados en la BNE provienen de la biblioteca del duque de Osuna, aunque no consta tal procedencia del de El mayor encanto, según apunta Sánchez Mariana, 1984, p. 126, con lo que bien podría ser el de Sancho Rayón. 
ni si Sancho Rayón o el marqués poseían el manuscrito entero o solo en parte $^{22}$.

Las dos jornadas conservadas en la Hispanic parecen haber sido acompañadas hace tiempo de una nota manuscrita a lápiz del marqués que ya no existe, pero que aún debió de ser vista por Alexander Parker el 14 de septiembre de 1961, según una ficha catalográfica que me facilitaron en la biblioteca. En esa nota manuscrita, y de acuerdo con la mencionada ficha, el marqués escribió: «MS. Autógrafo de Calderón de la Barca», y Parker consideró la noticia incorrecta. Resulta muy aventurado pensarlo, pero quizá el marqués tuviese todavía el manuscrito completo y su nota aludiese a la escena final reescrita por Calderón de su puño y letra a la que se hará alusión más tarde.

Más peso tiene el ya mencionado apunte de La Barrera en su Catálogo, que podría ser un indicio de que Sancho Rayón aún poseía el manuscrito entero. La Barrera ofrece en él una lista de manuscritos de obras de Calderón «que posee el señor don José Sancho Rayón» ${ }^{23}$ y que acabaron todos en la biblioteca de la Hispanic Society a través de la del marqués de Jerez de los Caballeros, tal y como se puede comprobar comparando las noticias que da La Barrera con los manuscritos que se pueden consultar hoy en la Hispanic ${ }^{24}$. Del manuscrito de El mayor encanto sólo decía La Barrera: "manuscrito antiguo, con una escena que se halla suprimida en todas las ediciones» ${ }^{25}$, mientras que del de El secreto a voces escribía: «manuscrito de la se-

22 Puede también apuntarse que, aunque gran parte de los libros de Sancho Rayón provenían de la biblioteca de Bartolomé José Gallardo, éste no parece haber poseído el manuscrito, pues no está recogido ni en el Ensayo de una biblioteca española de libros raros y curiosos, en cuya preparación participó Sancho Rayón (Gallardo, 1862), ni en la relación que da Rodríguez-Moñino, 1965, de manuscritos robados a Gallardo en 1823 o conservados por él.

23 C. A. de la Barrera, 1860, p. 513.

24 Se trata de los de Mejor está que estaba, El mayor encanto, amor, El secreto a voces y la «Loa sacramental alegórica de La Risa, para el auto de El diablo mudo, del mismo Calderón», en palabras de don Cayetano, 1860, p. 513. Sólo no se aprecia correspondencia con dos volúmenes de autos que cita a continuación La Barrera, séptima y octava parte, aunque muchos no parecen ser de Calderón, por lo que quizá estén en otro lugar del catálogo de la Hispanic.

25 C. A. de la Barrera, 1860, p. 513. 
gunda y tercera jornadas, con las licencias de $1668 »^{26}$, por lo que podría suponerse que de haber detectado que el de El mayor encanto, amor estaba también incompleto habría dejado constancia de ello, al igual que con El secreto a voces. Quizá cabría deducir, pues, que Sancho Rayón aún poseía el manuscrito completo, aunque es difícil saber con qué grado de atención miraría La Barrera estos textos.

Que la separación del manuscrito pudo haberse hecho con cierta facilidad se deduce de la noticia que se nos da en el catálogo de teatro de la Hispanic Society, donde se dice del manuscrito de El mayor encanto que «seems to have been part of a factitious volume. Traces of the binding are still visible on the spine. The ms of El José de las mujeres is also an arrachement from such a volume» ${ }^{27}$.

Si nos centramos ya en el texto, observamos en primer lugar que un mínimo de tres manos han participado. La comedia fue trasladada por el copista que, como se mencionó, Paz y Mélia había identificado con Matos Fragoso, aunque Sánchez Mariana rebatió tal afirmación, y que es el mismo que copió, entre otras obras, Los tres mayores prodigios y las jornadas segunda y tercera de El José de las mujeres. Una segunda mano de trazo grueso y que utiliza una tinta desvaída realizó distintas modificaciones sobre el texto copiado en primera instancia (aunque algunas de las correcciones parecen deberse ya al primer copista), y por último el mismo Calderón escribió unos versos del final.

Atendiendo por ahora sólo a lo trasladado por la primera mano, observamos que el manuscrito es copia o bien de QC o bien de $S$. Como indicios de ello están, en primer lugar, el que incluye, como ya se señaló, los versos cercanos al inicio de la comedia que fueron omitidos en $Q$ y las ediciones que de ella dependen, empezando por la de Vera Tassis. En segundo lugar los errores comunes con QC y $S$, como en los siguientes ejemplos:

${ }^{26}$ C. A. de la Barrera, 1860, p. 513. La noticia se corresponde con lo que escriben Regueiro y Reichenberger, 1984, t. I, p. 111, en el catálogo de manuscritos teatrales de la Hispanic.

${ }^{27}$ Regueiro y Reichenberger, 1984, vol. I, p. 90. 


$$
\text { QC / S }
$$

era para aquellos nube, y peñascos para estos, porque se daban la mano con uno y con otro estremo

(fol. 3v.b)

DUEÑA

ENANO

Clarín

Pues no faltará, si es ese el defeto. ¡Brunelillo!

Doña Brianda.

¿De dónde

sales, átomo viviente?

(fol. 13v.a)

Déjame, Astrea,

y no de joya me tientes, que me harás desesperar

(fol. 14v.b)

Aunque a tus voces se muevan mejor que al eco sonoro de Orfeo en troncos y fieras

(fol. 18r.a)

ven por la campaña azul de sus salobres cristales vagar un volcán deshecho, correr un Flegra portátil, correr un Etna movible, y ir una Tinacria errante.

(fol. 21v.b)

Ms.

era para aquellos nube, y peñascos para estos, porque se daban la mano 
con uno y con otro estremo

$$
(\text { fol. } 4 \mathrm{r})^{28}
$$

Dueña. Pues no faltará, si es ese el defecto. ¡Brunelillo!

\section{ENANO}

Doña Brianda.

Clarín ¿De dónde sales, átomo viviente?

(fol. 28v)

Déjame, Astrea, y no de joyas me mientes, que me harás desesperar

\section{(fol. 31r)}

Aunque a tus voces se muevan mejor que al eco sonoro de Orfeo en troncos y fieras

ven por la campaña azul de sus salobres cristales vagar un volcán deshecho, correr un Flegra portátil, correr un Etna movible, ya una Tinacria errante.

(fol. $\left.7 r^{\star}\right)$

\section{$V T$}

era para aquellos nube, y peñasco para estos, porque se daba la mano

${ }^{28}$ En la numeración de los folios del manuscrito sigo para las dos jornadas de la Hispanic Society la moderna a lápiz y para el fragmento de la Nacional la numeración de época; para distinguir los folios del fragmento de la BNE los señalaré con un asterisco. 
con uno y con otro estremo

$$
\text { (p. } 5 b)^{29}
$$

DUeÑA

ENANO

Pues no faltará, si es ese

el defecto. ¡Brunelillo!

Sal al punto.

ENANO

¿Qué me quieres,

doña Brianda?

Clarín

¿De dónde

sales, átomo viviente?

(p. 25b)

Déjame, Astrea,

y no de joya me tientes, que me harás desesperar si a hablar más en eso vuelves

(p. 27b)

Aunque a tus voces se muevan mejor que al eco sonoro de Orfeo troncos y fieras

$$
\text { (p. 34a) })^{30}
$$

ven por la campaña azul de sus salobres cristales vagar un volcán deshecho, mover un Flegra portátil, correr un Etna movible, $y$ ir una Trinacria errante.

$$
\text { (p. } 41 \mathrm{a})^{31}
$$

29 El sujeto es 'el palacio'; la concordancia se mantiene en "era» pero se rompe en «daban», quizá por influjo de los plurales del verso anterior; sólo Vera Tassis corrigió con acierto.

30 «Troncos y fieras» funciona como sujeto de «se muevan», por lo que la preposición «en» es incorrecta y de ahí la pertinencia de su eliminación por parte de Vera Tassis.

${ }^{31}$ Dejando al margen el error del manuscrito en el último verso citado, debe de ser errónea la reiteración de «correr» en dos versos seguidos de $Q C$, aspecto que fue mantenido en el manuscrito. Vera Tassis intentó subsanarlo introduciendo «mover» en uno de los versos. 
En otros casos la primera mano copió el error de $Q C$ y sólo una segunda mano lo corrigió, como en los pasajes que siguen:

$$
Q C / S
$$

y con razón, porque ya en callado fuego envuelto, cada aliento es un volcán, cada suspiro es un Etna.

(fol. 9v.a)

porque cosa tan pesada como una dueña, no puede sufrilla sino un gigante

(fol. 13v.b)

Vengativa y cruel, porque te asombres, a pesar de deidades y de fieras, reina desta república de fieras, señora deste piélago de hombres viví

(fol. 20r)

Ms. (primera mano)

y con razón, porque yo en callado fuego envuelto, cada aliento es un volcán, cada suspiro es un Etna.

(fol. 19v)

porque cosa tan pesada como una dueña, no puede sufrirla sino un gigante (fol. 29r)

Vengativa y cruel, porque te asombres, a pesar de deidades y de fieras, 
reina desta república de fieras, señora deste piélago de hombres viví

(fol. $\left.4 v^{\star}\right)$

Ms. (segunda mano)

y con razón, porque yo en callado fuego envuelta, cada aliento es un volcán, cada suspiro es un Etna ${ }^{32}$

porque cosa tan pesada como una dueña, no puede sufrirla sino un gigante, una suegra y una sierpe. ${ }^{33}$

Vengativa y cruel, porque te asombres, a pesar de deidades y de esferas, reina desta república de fieras, señora deste piélago de hombres viví3

Un tercer elemento que parece probar que el texto seguido en el manuscrito es el de QC o $S$ lo constituye un error de copia de unos versos que se repiten dos veces en $M s$. Se trata de los siguientes, que en QC están puestos en boca de Circe:

32 La primera mano del manuscrito copió «envuelto», como en $Q C$, aunque una segunda corrigió en "envuelta», lectura también presente en $V T$ y con la que se respeta tanto la rima como el sentido, pues el referente es Circe.

${ }^{33}$ Frente a las otras lagunas de QC ya vistas que fueron mantenidas en $M s$, en este caso una segunda mano añadió al margen un verso que encaja bastante bien en el contexto; Vera, por su parte, añadió: «y dos bestias solamente».

${ }^{34} \mathrm{La}$ repetición de «fieras" en posición de rima de los versos segundo y tercero de un soneto en $Q C$ y $S$ parece deberse claramente a un error, que fue mantenido en el manuscrito. Sin embargo, una segunda mano tachó "fieras» y lo sustituyó con eficacia por «esferas» en el segundo verso. Vera Tassis, menos inspirado, cambió «y de fieras» por «linsonjeras», con lo que editó: «a pesar de deidades lisonjeras». 


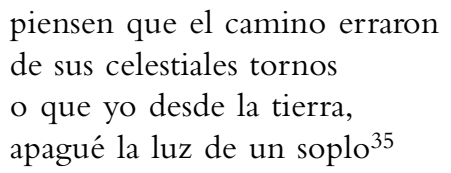

En el manuscrito estos versos fueron copiados dos veces, la segunda en el mismo sitio que en $Q C$; pero ya habían aparecido poco antes tras un parlamento de Arsidas que dice así:

$\quad$ ¡Y aquí
de Tinacria! Que aunque solo
me ves, mis vasallos son
estos brutos y estos troncos.
¡Fieras de Tinacria humanas,
dad a vuestro rey socorro! ${ }^{36}$

Como se puede apreciar, los versos de $Q C$ citados en primer lugar no tienen ningún sentido al final de este parlamento de Arsidas, por lo que la razón de haber sido copiados ahí parece ser mecánica. En efecto, los cuatro versos de $Q C$ que aparecen dos veces en el manuscrito están al principio de la segunda columna del recto del folio 18 en $Q C$, justo a la derecha del parlamento de Arsidas, que inicia la primera columna del folio. Tras este parlamento se incluye en $Q C$ una larga acotación con una línea en blanco antes y otra después, por lo que quizá el amanuense se despistase y, en lugar de seguir la columna hacia abajo, pasase a la izquierda y copiase los cuatro versos mencionados, aunque luego sí volviese de nuevo a la columna de la izquierda y más tarde reprodujese esos cuatro versos una segunda vez.

La disposición de la página es análoga en $Q C$ y $S$, por lo que el error de copia del manuscrito se explica perfectamente si se considera que se seguía una de estas dos ediciones. Sin embargo, y a pesar de lo próximos que están, en general, los textos de $Q C$ y $S$, el siguiente lugar parece mostrar que el seguido por el manuscrito fue el de $S$ :

35 Calderón de la Barca, Segunda parte de comedias, fol. 18r.b.

36 Calderón de la Barca, Segunda parte de comedias, fols 17v.b-18r.a. 


\section{QC}

unas mismas ondas hacen

las espumas y las matas

(fol. 20r.a)

$S$

unas mismas ondas

las espumas y las matas

(fol. 20r.a)

QC

unas mismas ondas son

las espumas y las matas

(fol. 3v)

Como se puede apreciar, la omisión de "hacen» en $S$ fue corregida en el manuscrito con "son», lectura que hace sentido aunque difiere de la de $Q C$ y, por tanto, parece una enmienda realizada para rellenar la laguna del texto base.

A pesar de esta dependencia de $S$, el manuscrito corrige a veces con eficacia malas lecturas de la parte, en unas ocasiones coincidiendo con otros testimonios, sobre todo en los errores más evidentes, en otras aportando soluciones propias, más o menos felices. Valgan los siguientes ejemplos:

$$
Q C / S
$$

Apenas de sus licores

el veneno admitió al pecho, cuando corrió al corazón

$$
\text { (fol. 4r.a) }
$$

hurtando en ecos suaves

las cláusulas de las aves, 
los compases a las fuentes.

(fol. 5r.a)

Basta decir que seguro de tus castigos atroces, tuvimos por agradables de los vientos los rigores

(fol. 6v.b)

Ms.

$\mathrm{Y}$ apenas de sus licores

el veneno admitió el pecho, cuando corrió al corazón

(fol. $4 \mathrm{v})$

hurtando en ecos suaves

las cláusulas a las aves,

los compases a las fuentes.

(fol. $7 \mathrm{rv}$ )

Basta decir que seguro de sus castigos atroces, tuvimos por agradables de los vientos los rigores

$(\text { fol. } 9 \mathrm{v})^{37}$

Sin embargo, estas valiosas enmiendas al texto de $Q C$ no deben llevar a pensar que el texto del manuscrito está en mejores circunstancias que el de la parte, pues, al contrario, son muchos más los pasajes en los que incorpora un error donde QC y $S$ no lo tenían. Sirvan de muestra, entre otros, los siguientes ejemplos:

37 Ulises está hablando con Circe, a quien le cuenta sus sucesos con Polifemo, referente de ese «sus». 


\section{$Q C / S$}

que yo seré el primero

que éste derribe, revellín grosero

que el paso a mis intentos contradice.

(fol. $2 \mathrm{v}$ )

Danteo ama a Lisis bella,

y Lisis manda a Danteo

disimular su deseo;

Silvio olvida a Clórida, y ella

manda que finja querella

(fol. 11r.b)

¿Hay más penas que por mí pasen este instante?

LíSIDAS

Sí

(fol. 12v.b)

LEBrel Aquesta cadena escojo, y esta para ti se quede.

Clarín ¿Ca... qué?

LEBREL

Cadena; y agora

de diamantes este fénix.

(fol. 14r.b)

Ms.

que yo seré el primero

que éste derribe, rebelión grosero

que el paso a mis intentos contradice.

$(\text { fol. } 2 \mathrm{v})^{38}$

Silvio ama a Lisis bella,

y Lisis ama a Danteo;

disimular su deseo

38 El copista no parece haber entendido la palabra «revellín», escrita con $b$ en QC y $S$ («rebellin»), y la sustituyó por «rebelión», que no hace sentido. Con «éste» se alude a un árbol que se encuentra Ulises en el camino. 
a Silvio manda y a ella

manda que finja querrella

$(\text { fol. } 23 \mathrm{v})^{39}$

¿Hay más penas que por mí pasen en este instante?

LÍSIDAS Sí

(fol. 26v)

LEBREL

Aquesta cadena escojo,

Clarín $\mathrm{y}$ esta para ti se quede.

LEBREL ¿Ca... qué? $\mathrm{Y}$ ahora de diamantes este fenis.

(fols. 29v-30r)

En otro lugar, el manuscrito omite un pasaje de ocho versos de la parte, quizá por razones de autocensura. Es el siguiente:

$\begin{array}{ll}\text { Astrea } & \text { (Holgareme de salir } \\ & \text { de religión tan estrecha } \\ & \text { como es el honor. Vestales } \\ & \text { vírgenes Diana celebra } \\ & \text { entre gentes, mas nosotras } \\ & \text { entre animales y fieras } \\ & \text { somos vírgenes bestiales). } \\ & (\text { Calla, porque no lo entienda })^{40} .\end{array}$

En otros lugares el texto copiado por la primera mano se desvía de $Q C$ y $S$, pero una segunda corrige y recupera en muchas ocasiones la lectura de la parte, aunque no siempre tenga que haber un error

${ }^{39}$ Las variantes de $M s$. en este pasaje resultan, cuando menos, curiosas. En QC la situación, que se corresponde con un plan de Circe contado en clave, está clara: uno que quiere tiene que fingir que no quiere (Danteo) y uno que no quiere tiene que fingir que quiere (Silvio), y a partir de ahí se planteará la cuestión de qué situación es peor. En Ms. la situación se convierte, sin embargo, en un triángulo bastante confuso. Quizá todo el aparato de variantes de $M s$. se montase a raíz de la hipermetría del verso "Silvio olvida a Clórida y ella» (que Vera Tassis salvó, simplemente, editando «Clori»), lo que llevó a una serie de cambios que dejaron el texto sin sentido.

${ }^{40}$ Calderón de la Barca, Segunda parte de comedias, fol. 9r.b. 
en la del manuscrito. Algunas de las correcciones bien pudieron haberse hecho ope ingenii, pero otras delatan que se tuvo en cuenta el texto de la parte:

\section{QC}

¿Pues cómo,

a dos afectos atenta,

quieres que olvide a quien quiero

y que a quien olvido quiera?

(fol. 9v.b)

Duelos del ingenio no

el acero los lidió.

(fol. 11v.b)

Yo disimulo que no

te quiero, pues me obligó

tu precepto.

(fol. 12r.a)

llevaré la caja; pues

ahora veo claramente

por qué el gigante la trujo

(fol. 13v.b)

LeBrel ¿Qué quieres

decir en eso?

Clarín No sé;

tú lo verás si la abrieres.

(fol. 14r.a)

Ms. (primera mano)

¿Pues cómo,

a dos afectos atenta,

quieres que olvido a quien quiero

y que a quien olvido quiera?

(fol. 20v) 
De celos del ingenio no el acero los lidió.

(fol. 24v)

Yo disimularé que no

te quiero, pues me obligó

tu precepto.

(fol. 25r)

llevaré la caja a cuestas;

ahora veo claramente

por qué el gigante la trujo

(fol. 29r)

LEBREL

¿Qué quieres

decir en eso?

Clarín No lo sé;

tú lo verás si la abrieres.

(fol. 29v).

Ms. (segunda mano)

¿Pues cómo,

a dos afectos atenta,

quieres que olvide a quien quiero

y que a quien olvide quiera? ${ }^{41}$

Duelos del ingenio no

el acero los lidió.

Yo disimulo que no

te quiero, pues me obligó

tu precepto.

${ }^{41}$ Este lugar es muy curioso. La primera mano de $M s$ sólo se desvió de QC y $S$ por copiar «olvido» en lugar de "olvide» en el tercer verso citado. Una segunda mano se dio cuenta del error y lo corrigió en «olvide», recuperando la lectura de la parte, aunque realizó la misma operación en el último "olvido», que sí era correcto, estropeando la lectura. 
llevaré la caja; pues

ahora veo claramente

por qué el gigante la trujo ${ }^{42}$

LEBREL ¿Qué quieres

decir en eso?

Clarín No sé;

tú lo verás si la abrieres.

En otras ocasiones la segunda mano devuelve el sentido al texto, deturpado por la primera, aunque no se recupere la lectura de QC y S:

$$
\text { QC / S }
$$

Dices bien,

pues solo en ellos descansa

el alma, porque ellos solo

el centro han sido del alma.

(fol. 20r.a)

Ms. (primera mano)

Dices bien,

pues solo en ellos descansa

el alma, que por ellos solo

el centro han sido del alma.

(fol. $4 r^{\star}$ )

Ms. (segunda mano)

Dices bien,

pues solo en ellos descansa

el alma, pues ellos solo

el centro han sido del alma.

42 En este pasaje la corrección parece haber sido hecha con $S$ a la vista, pues no resultaba tan evidente, e incluso se podría salvar «a cuestas» con una puntuación fuerte después. 
En otros lugares la lectura de la primera mano no era muy afortunada, pero la intervención de la segunda no mejora las cosas:

$$
\text { QC / S }
$$

Antistes aquí se quede para prevenir que es salva que a Circe hace nuestra gente.

(fol. 19r.a)

Ms. (primera mano)

Antistes aquí se quede para prevenir que salga que a Circe.

$\left(\right.$ fol. $\left.2 r^{\star}\right)$

Ms. (segunda mano)

Antistes aquí se quede para prevenir que $[$ a ver $]$ salga que a Circe hace nuestra gente ${ }^{43}$.

El manuscrito presenta también diversas lecturas adiáforas con respecto al texto de QC y $S$. En muchos casos se trata de meras variantes de orden sintáctico o variaciones en los pronombres demostrativos, tiempos verbales o número de las palabras. En otras ocasiones las variantes son de mayor relieve, como pueden ser las siguientes:

${ }^{43}$ La lectura buena de $Q C$ y $S$ es copiada mal en $M s$, primero porque se omite parte del tercer verso, segundo por «salga», quizá resultado de no haber entendido «salva». En todo caso, una segunda mano completó el tercer verso de acuerdo con $Q C$, pero se dejó el "salga» del verso anterior. Con letra diminuta parece se quiso escribir «ver» antes de «salga», quizá con la intención de que dijese "que a ver» o "que a ver salga», lecturas que no resultan muy felices en ningún caso. 


\section{QC / S}

Y en él

está la ninfa pendiendo, embajatriz de las diosas, reina de dos elementos.

(fol. 4v.a)

Pues nos dejó Circe, y pues

a puerta cerrada estamos, $\mathrm{y}$ tan solos nos hablamos, tiempo, doña Marta, es de tomar una lición.

(fol. 23v.a)

Ms.

Y en él

está la ninfa pendiendo, embajatriz de las ninfas, reina de los elementos.

(fol. 6r)

Pues nos dejó Circe, y pues

a puerta cerrada estamos, y tan solos nos hallamos, tiempo, doña Marta, es de tomar una lición

(fol. 10r ${ }^{\star}$ )

En otros pasajes es la segunda mano la que introduce variantes, también correctas, en buenas lecturas de QC:

$$
Q C / S
$$

yo voto a tu deidad aras y altares si la cólera aplacas destos mares

(fol. 1r)

y el que en la experiencia hiciere 
primera demostración, por premio de la cuestión una rica joya espere.

(fol. 11v-b)

Ms. (primera mano)

yo voto a tu deidad aras y altares si la cólera aplacas destos mares

(fol. 1r)

y el que en la esperencia hiciere primera demostración, por premio de la cuestión una rica joya espere.

(fol. 24v)

Ms. (segunda mano)

yo ofresco a tu deidad aras y altares si la cólera aplacas destos mares ${ }^{44}$

y el que en la esperencia hiciere primera demostración, por premio de la cuestión un noble favor espere.

Se puede apreciar, pues, que las intervenciones de la segunda mano son variadas.

Incluye asimismo algún añadido de la indicación de música ${ }^{45}$ y en otros lugares actúa en mayor grado, con supresiones de versos y añadidos de algún otro.

${ }^{44}$ Aquí, curiosamente, la variante introducida por la segunda mano, seseante, es más calderoniana que el texto primero, pues una consulta al TESO muestra la rareza de la construcción votar + Cdir + Cind (se emplea mucho "voto" pero como sustantivo), en tanto que la que incluye «ofrecer» es más frecuente.

${ }^{4}$ Así sucede en los folios 5v, 6v (donde se dice «Tocan guitarra»), 22v ó 33v. 
Dejando al margen otros atajos salpicados a lo largo de la comedia y que suelen afectar a versos puestos en boca de los graciosos o a fragmentos de relaciones extensas, otros muchos se concentran en la escena final de la segunda jornada, en la que Circe hace aparecer una mesa ricamente dispuesta para una cena. En el manuscrito todos los versos que aluden a la cena son sistemáticamente atajados o tachados hasta un total de 54 , quizá por dificultades de representación debido a los distintos efectos que serían necesarios. De nuevo dos de los versos, que incluyen una alusión a la cena, son sustituidos por otros dos situados al margen:

$$
\text { QC / S }
$$

Hola, cantad, cantad y divertido uno y otro sentido esté con las viandas y las voces que suenen en los céfiros veloces.

(fol. 17r)

Ms. (primera mano)

Hola, cantad, cantad y divertido uno y otro sentido estén con las viandas y las voces que suenen en los céfiros veloces.

(fol. 34r)

Ms. (segunda mano)

Hola, cantad, cantad y divertido uno y otro sentido estén mientras mi ciencia examina en los dos nueva experiencia.

Otro grupo de versos atajados y con una alternativa se encuentra en la tercera jornada, al término de la comedia. Todos los versos del remate, excepto los dos últimos, fueron tachados, hasta un total de 34. Se trata de la apoteosis final, en la que los palacios de Circe se hunden y sirenas y tritones lo celebran con regocijos y festines. Por po- 
sibles dificultades de representación, estos versos fueron sustituidos por otros no tan complejos y que fueron escritos, como ya puso de relieve Sánchez Mariana, por el mismo Calderón con una tinta muy tenue que dificulta su lectura. El final de la comedia en el manuscrito queda asít

Circe

[Astrea]

[Libia]

[Astrea]

[Libia]

¿Astrea?
Si del mar eres deidad, cuando en él mis fuerzas quites, ya que no pudo mi ciencia vengarme en quien huyó libre, en mí podré. Estos palacios, que mágico el arte finge, desvanecido sin polvo sola una voz los derribe.

Oye.

Aguarda.

Escucha. Espera.

Detenerla es imposible que precipitada al mar se arroja porque se mire que los de amor paran en trágicos fines

encantos [corrige]

Sin embargo, y como ya apuntó Sánchez Mariana para la tercera jornada y se deduce de lo que he visto en el manuscrito de la Hispanic Society, la intervención de Calderón parece haberse limitado a esos versos, a pesar de que la tinta de muchas de las intervenciones de la segunda mano se asemeja a la calderoniana. Quizá el autor de comedias encargado de la representación pidiese al dramaturgo unos versos para ese final y Calderón no tuviese tiempo de más, o le faltase interés. Por esos mismos años reescribió en profundidad El mayor monstruo del mundo dando lugar a una nueva versión de la comedia, más espectacular y adecuada para una suntuosa representación palaciega ${ }^{47}$,

46 Señalo en cursiva los versos de QC con los que enlaza el autógrafo calderoniano, para el que sigo la plausible reconstrucción de Sánchez Mariana, 1984, p. 124, que deduce quién dice los versos, algo no indicado explícitamente en el manuscrito.

47 Sobre las dos versiones de El mayor monstruo puede verse Caamaño, 2006. 
y quizá El mayor encanto, amor, comedia que ya desde un principio había sido concebida para la corte, no necesitase ese lavado de cara. Las hipótesis podrían ser muchas ${ }^{48}$.

Puede aventurarse también una posible identidad de la segunda mano de este manuscrito de El mayor encanto, pues, aunque las muestras de letra no sean abundantes, parece coincidir en sus rasgos con la letra del copista de la primera jornada del manuscrito de El José de las mujeres que se conserva en la Hispanic Society y cuyas jornadas segunda y tercera fueron copiadas por el mismo copista de El mayor encanto y Los tres mayores prodigios.

En suma, y tras lo visto, el texto de la edición príncipe de la Segunda parte de comedias de Calderón, aunque debe seguir siendo tomado como base en una edición crítica de la comedia, no resulta tan satisfactorio como podrían hacer suponer la cercanía de su composición y representación a la fecha de publicación, así como su presumible mantenimiento en la órbita calderoniana durante el proceso tanto de representación como de edición. El texto es, de hecho, peor que el de casi cualquier otra comedia de la misma parte.

Para subsanar algunos de sus errores contamos con un manuscrito de 1668 que, entre otras rarezas, cuenta con el interés añadido de incluir un autógrafo calderoniano en su último folio, aunque la intervención de don Pedro no parece haber ido más allá de esos versos. Por lo demás, el manuscrito permite, bien a través de su primera mano, bien a través de la segunda, corregir con eficacia varias de las malas lecturas del texto impreso, aunque otras las mantiene e incluso añade abundantes errores nuevos.

48 Alteraciones como las que se acaban de señalar, y que suelen coincidir con el final de la comedia o de una jornada, fueron estudiadas por Margaret Rich Greer en un artículo de 1984 en el que analiza con detalle distintas comedias que presentan este tipo de modificaciones, así como su posible procedencia y validez. La autora incluye también en su trabajo, 1984, pp. 75-76, el caso de la tercera jornada de El mayor encanto, amor, que pone en relación con el de Basta callar, comedia de la que se conserva un manuscrito (BNE Res. 91) trasladado por un copista pero con intervenciones autógrafas de Calderón, a cuya mano se deben, por ejemplo, las líneas finales de la primera jornada. Ruano de la Haza, 1978, pp. 72-77, ofrece ejemplos asimismo de cómo Calderón modificó en distinto grado y de su puño y letra algunos lugares de El postrer duelo de España (ms. 15.273 BNE) y Cada uno para sí (ms. 16.887 $\mathrm{BNE}$ ) en pasajes copiados por Sebastián de Alarcón. 
En lo que respecta a los versos autógrafos de Calderón, que constituyen un cierre de la comedia alternativo al publicado en 1637, han de ser tratados como una nueva versión de ese final, motivada posiblemente por dificultades en la representación, y por tanto no han de ser mezclados en ningún caso con los versos del final original, que ha de ser el editado si se quiere una aproximación a El mayor encanto de 1635-1637. Los nuevos versos calderonianos han de ser incluidos en el aparato crítico como texto variante. 


\section{Bibliografía}

Barrera y Leirado, C. A. de la, Catálogo bibliográfico y biográfico del teatro antiguo español desde sus orígenes hasta mediados del siglo XVIII, Madrid, Imprenta y estereotipia de M. Rivadeneyra, 1860; edición facsímil, Madrid, Gredos, 1969.

CaAmaño Rojo, M. J., Edición crítica de "El mayor monstruo del mundo», de Calderón, Tesis de Doctorado dirigida por Santiago Fernández Mosquera, Santiago de Compostela, Universidad de Santiago de Compostela, junio 2006.

Calderón de la Barca, P., Segunda parte de comedias, Madrid, 1637, en Comedias, a facsimile edition prepared by D. W. Cruickshank and J. E. Varey, London, Gregg international publishers / Tamesis books, 1973, vol. $\mathrm{V}$.

De Armas, F., "The Maids of Autumn», en The Return of Astraea: an AstralImperial Myth in Calderón, Lexington, The University Press of Kentucky, 1986, pp. 139-163.

Fernández Mosquera, S., «Defensa e ilustración de la Segunda parte (1637) de Calderón de la Barca», en Estudios de teatro español y novohispano, eds. M. Romanos, X. González y F. Calvo, Buenos Aires, Universidad de Buenos Aires / AITENSO, 2005, pp. 303-325.

- «Libertad hermenéutica y modernidad: las primeras fiestas cortesanas de Calderón», en El Siglo de Oro en escena. Homenaje a Marc Vitse, en prensa a.

- «El significado de las primeras fiestas cortesanas de Calderón de la Barca», en El pensamiento ideológico y cultural de su época: XIV Coloquio Anglogermano sobre Calderón. Heidelberg, 24-28 de julio de 2005, en prensa b.

- ed., P. Calderón de la Barca, Segunda parte de comedias, Madrid, Biblioteca Castro, en prensa c.

Gallardo, B. J., Ensayo de una biblioteca española de libros raros y curiosos, edición facsímil, Madrid, Gredos, 1968 (4 vols.)

Greer, M. R., "Calderón, Copyists, and the Problem of Endings», Bulletin of the Comediantes, 36, 1, 1984, pp. 71-81.

- «Power at Play: El mayor encanto, amor», en The Play of Power. Mythological court dramas of Calderón de la Barca, Princeton, Princeton University Press, 1991, pp. 77-95; traducido como «El poder en juego: El mayor encanto, amor», en Estudios sobre Calderón, ed. J. Aparicio Maydeu, Madrid, Istmo, 2000, vol. I, pp. 649-680.

Hartzenbusch, J. E., ed., P. Calderón de la Barca, Comedias. Tomo I, Madrid, Atlas, 1944.

Heaton, H. C., «On the Segunda parte of Calderón», Hispanic Review, 5, 1937, pp. 208-224. 
Paz y Mélia, A. y J. Paz, Catálogo de las piezas de teatro que se conservan en el Departamento de Manuscritos de la Biblioteca Nacional. Tomo I, Madrid, Blass S. A. Tipográfica, 1934.

Regueiro, J. M., y A. G. Reichenberger, Spanish Drama of the Golden Age, a catalogue of the manuscript collection at the Hispanic Society of America, New York, The Hispanic Society of America, 1984, 2 tomos.

Rodríguez-Gallego, F., "Noticia de las dos versiones de El astrólogo fingido de Calderón de la Barca», en Campus Stellae. Haciendo camino en la investigación literaria, coord. D. Fernández López y F. Rodríguez-Gallego, Santiago de Compostela, Universidad de Santiago de Compostela, 2006 (2 tomos), t. I, pp. 456-465.

Rodríguez-Moñino, A., Historia de una infamia bibliográfica (la de San Antonio de 1823), Madrid, Castalia, 1965.

- «El marqués de Jerez de los Caballeros. Semblanza de un gran bibliófilo», en Catálogo de la biblioteca del marqués de Jerez de los Caballeros, reimpreso por primera vez en facsímile, precedido de una biografía del gran bibliófilo por Antonio Rodríguez-Moñino, Madrid, Librería para bibliófilos, 1966, pp. 7-78.

Ruano de la Haza, J. M., «Two Seventeenth-Century Scribes of Calderón», Modern Language Review, 73, 1978, pp. 71-81.

SÁnChez MARiana, M., "Un manuscrito calderoniano desconocido (con una digresión sobre los autógrafos de Matos Fragoso)", Revista de Literatura, 46, 91, 1984, pp. 121-130.

- ed., Catálogo de las piezas de teatro que se conservan en el gabinete de manuscritos de la Biblioteca Nacional. Tomo III (suplemento e indices), Madrid, Ministerio de Cultura / Dirección general del libro, 1989.

- «Los manuscritos dramáticos del Siglo de Oro», en Ex libris. Homenaje al profesor Fradejas Lebrero, ed. J. Romera Castillo y otros, Madrid, UNED, 1993, t. I, pp. 441-452.

Shergold, N. D., «The First Performance of Calderón's El mayor encanto amon», Bulletin of Spanish Studies, 35, 1958, pp. 24-27.

Sloman, A. E., "The Missing Lines of El mayor encanto amor», en Studia Philologica. Homenaje ofrecido a Dámaso Alonso por sus amigos y discípulos con ocasión de su $60^{\circ}$ aniversario, Madrid, Gredos, 1963, vol. III, pp. 425-30.

Teatro español del Siglo de Oro (TESO), CD-Rom, ed. C. Simón Palmer, Madrid, Chadwyck-Healey España, 1998.

Toro y Gisbert, M. de, "¿Conocemos el texto verdadero de las comedias de Calderón?», Boletín de la Real Academia Española, 5, 1918, pp. 401-421.

Valbuena Briones, A., ed., P. Calderón de la Barca, El mayor encanto, amor, en Obras completas. Dramas, Madrid, Aguilar, 1966, pp. 1507-1545.

Vega García-Luengos, G., «Calderón, nuestro problema (bibliográfico y textual): más aportaciones sobre las comedias de la Segunda parte», en Ayer y 
hoy de Calderón. Actas seleccionadas del Congreso Internacional celebrado en Ottawa del 4 al 8 de octubre del 2000, ed. J. M. ${ }^{a}$ Ruano de la Haza y J. Pérez Magallón, Madrid, Castalia, 2002, pp. 37-62. 
